\title{
An experimental method to study emissions from heated tobacco between $100-200^{\circ} \mathrm{C}$
}

\author{
Mark Forster, Chuan Liu*, Martin G Duke, Kevin G McAdam and Christopher J Proctor
}

\begin{abstract}
Background: Cigarette smoke emissions are mainly produced by distillation, pyrolysis and combustion reactions when the tobacco is burnt. Some studies have shown that heating tobacco to temperatures below pyrolysis and combustion temperatures has the potential to reduce or eliminate some toxicants found in cigarette smoke. In this study, we designed a bench-top tube furnace that heats tobacco between $100-200^{\circ} \mathrm{C}$ and systematically studied the effects of heating temperatures on selected gas phase and aerosol phase compounds using an ISO machine-smoking protocol.

Results: Among a list of target chemical compounds, seven toxicants (nicotine, carbon monoxide, acetaldehyde, crotonaldehyde, formaldehyde, NNN and NNK) were quantifiable but not at all temperatures examined. The levels of the compounds generally displayed an increasing trend with increasing temperatures. The observed carbon monoxide and aldehydes represented the initial thermal breakdown products from the tobacco constituents. Water was the largest measured component in the total aerosol phase collected and appeared to be mainly released by evaporation; nicotine release characteristics were consistent with bond breaking and evaporation. Quantifiable levels of NNK and NNN were thought to be the result of evaporative transfer from the tobacco blend.

Conclusions: These results demonstrate the practical utility of this tool to study low-temperature toxicant formation and emission from heated tobacco. Between 100 to $200^{\circ} \mathrm{C}$, nicotine and some cigarette smoke compounds were released as a result of evaporative transfer or initial thermal decomposition from the tobacco blend.
\end{abstract}

Keywords: Tobacco heating, Aerosol, Emission, Toxicant

\section{Background}

Cigarette smoke is a highly complex aerosol system [1], involving over 6,000 identified chemicals in a dynamic and reactive mixture $[2,3]$. These chemicals are generated by incomplete combustion of tobacco that burns in either smouldering or puffing modes. Research efforts aimed at modifying combustion conditions with the aim of reducing smoke toxicity have so far proven difficult [4]. An alternative way to reduce the generation of toxicants from tobacco product is to heat rather than burn tobacco (sometimes referred to as heat-not-burn technologies). This has been tried in two ways. The first approach involves a lit carbon tip that heats incoming air, which in turn heats tobacco-based substrates in a form of cigarette-like product, forming an aerosol containing

* Correspondence: Chuan_Liu@bat.com

GR\&D Centre, British American Tobacco, Regents Park Road, Southampton SO15 8TL, UK

\section{Chemistry Central}

mainly water, glycerol, nicotine and volatile tobacco components $[5,6]$. Another approach uses a battery-powered smoking device containing a specially designed tobacco rod [7-11]. In both cases, the tobacco heating temperatures are typically below $300^{\circ} \mathrm{C}$, enough to release nicotine but not high as to cause significant pyrolysis. Studies based on these two types of technology have generally shown that the aerosol composition is somewhat simpler than that found in cigarette smoke $[6,11,12]$.

Studies to understand low-temperature tobacco thermochemistry have shown that the nicotine organic salts, the natural and stable form of nicotine in the tobacco leaf, begin to release nicotine above ca. $150^{\circ} \mathrm{C}$ [13-15]. Historically, pyrolysis studies on tobacco and tobacco ingredients have been performed around temperature ranges in the pyrolysis and combustion zones of the burning tip of a cigarette - typically above $500^{\circ} \mathrm{C}$ and up to $1000^{\circ} \mathrm{C}$ $[16,17]$. This is because most of the particulate phase 
components (collectively known as tar) in cigarette smoke are produced by thermal reactions within the tobacco rod at these temperatures. Many pyrolysis studies have examined both qualitative and quantitative relationships between different tobacco leaf and leaf ingredients (as possible precursors to smoke components) and smoke constituents of interests [18-25]. Data resulting from these studies have been useful in assessing whether or to what extent a specific ingredient or precursor will undergo thermal decomposition, their tendency to be transferred to the smoke intact, or possibly form a smoke constituent. In contrast, studies of the thermochemistry of tobacco heated to lower temperatures (under $300^{\circ} \mathrm{C}$ ) are not common. The ones published are usually based on a specific product $[11,12]$, hence their use in understanding aspects of low-temperature tobacco thermochemistry is limited. In this study, we examined levels of selected emissions in the aerosol produced by heating tobacco between 100 and $200^{\circ} \mathrm{C}$ to better understand aerosol properties from low-temperature tobacco heating. For this purpose, we developed a bench-top furnace for aerosol generation and collection from controlled tobacco heating. The focus of the investigation was on the lowtemperature releasing mechanisms for some known compounds typically associated with tobacco.

\section{Results and discussion}

\section{Thermogravimetric analysis (TGA)}

The TGA results up to $300^{\circ} \mathrm{C}$ are plotted in Figure 1 . The rate of weight loss $(-\mathrm{dG} / \mathrm{dT})$ began with a significant weight loss up to $100^{\circ} \mathrm{C}$ due to the release of free or physically bound water, with a second major weight loss occurring over a relatively broad temperature range above ca. $200^{\circ} \mathrm{C}$. The water loss around $100^{\circ} \mathrm{C}$ accounted for approximately $7 \%$ of the weight loss. At the end of $200^{\circ} \mathrm{C}$, the samples had lost about $17 \%$ of their initial weight which was more than the $11 \%$ moisture content, suggesting thermal evaporation and possibly onset of some initial thermal decomposition of some tobacco constituents $[16,18,19]$. The heating rates used in Figure 1 are significantly slower than those typically found in a burning cigarette during a puff where the tobacco heating rate can exceed a few hundred degrees per second [1]. Within the range of heating rates studied, there was no discernable weight loss trend in Figure 1, however, the 1st derivative of the weight loss showed a temporary plateau around $100^{\circ} \mathrm{C}$ and a gentle reflection point between 280 to $320^{\circ} \mathrm{C}$.

Figure 2 shows the temperature responses from the heater and also the centre of the tobacco rod at two set heater temperatures, 100 and $200^{\circ} \mathrm{C}$. Apart from minor fluctuations, the heater temperatures tracked the set temperature within $\pm 5^{\circ} \mathrm{C}$. When the furnace was set at $100^{\circ} \mathrm{C}$, the centre of the tobacco rod reached this temperature (within $~ 5 \%$ ) after about $120 \mathrm{~s}$. As the heat was supplied by conduction and radiation from the peripheral surface, this measurement point was the last part of the tobacco rod to achieve the target temperature. A puff at $120 \mathrm{~s}$ created a sudden and significant temperature drop, most likely due to the cooling effect by incoming air and nearly $60 \mathrm{~s}$ was required for the temperature to recover to $100^{\circ} \mathrm{C}$. This temperature drop by puffing became progressively less significant in the later puffs, probably as a result of larger amount of energy stored within the

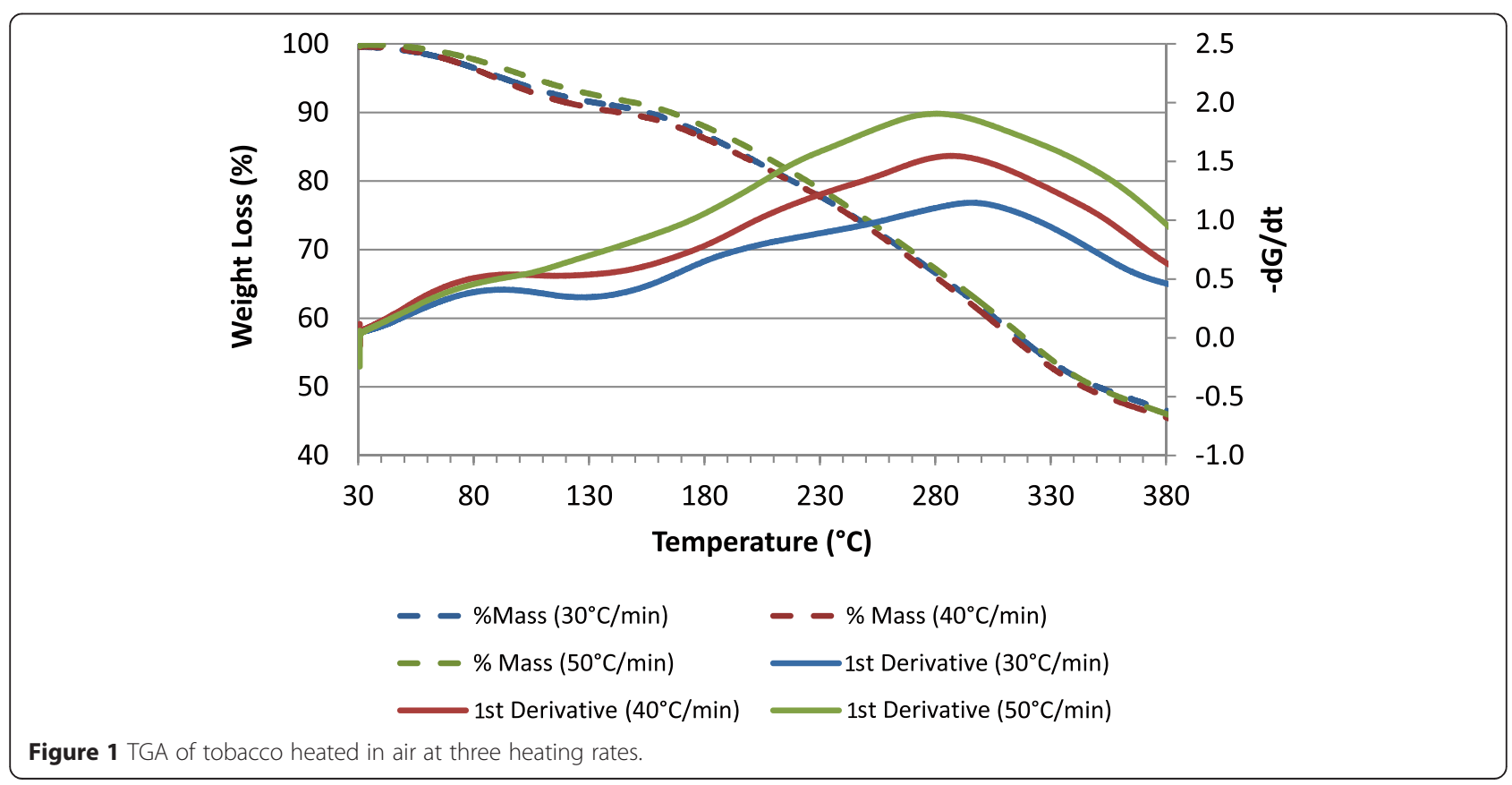




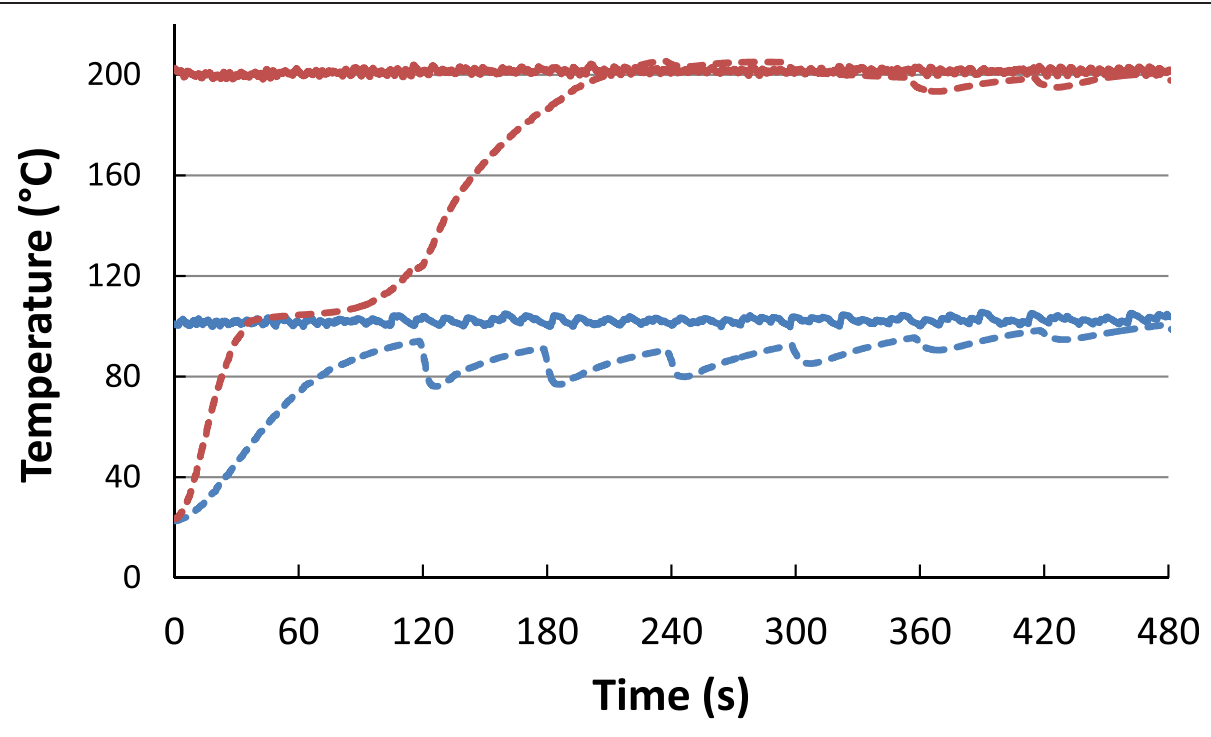

Av. Heater Temp. $\left(100^{\circ} \mathrm{C}\right)$
- Av. Tobacco Rod Centre Temp. $\left(100^{\circ} \mathrm{C}\right)$
- Av. Heater Temp. $\left(200^{\circ} \mathrm{C}\right)$
- Av. Tobacco Rod Centre Temp. $\left(200^{\circ} \mathrm{C}\right)$

Figure 2 Temperature profiles of the heating chamber of the furnace (solid lines) and the centre of the tobacco rod (dashed lines) at 100 and $200^{\circ} \mathrm{C}$.

tobacco rod combined with less amount of water available to release.

When the furnace was set at $200^{\circ} \mathrm{C}$, the initial temperature gradient achieved by the rod centre was greater than that set at $100^{\circ} \mathrm{C}$, representing a faster heat up of the rod. However, this temperature rise stopped abruptly around $100^{\circ} \mathrm{C}$ and remained there for nearly $60 \mathrm{~s}$. This temporary temperature plateau not only occurred when the furnace was set at $200^{\circ} \mathrm{C}$ but also observed at the other set temperatures above $100^{\circ} \mathrm{C}$ (not shown), thus it can be attributed to the energy required to release the water from the tobacco rod, about $7 \%$ as measured by the TGA results in Figure 1 . At the $200^{\circ} \mathrm{C}$ heater temperature, once the temperature rise proceeded beyond this plateau, the magnitude of the temperature drop caused by puffing was very small. The main thermophysical processes responsible for aerosol release from a peripherally heated tobacco are significantly different as those seen in a lit cigarette as described by Baker $[1,4]$. In Figure 2, the heat is supplied from the outer surface of the tobacco along the length of the rod and the aerosol produced during a puff is the result of the heating of the tobacco rod during the period prior to the puff. Puffing simply transports pre-formed aerosol outside of the tobacco rod.

\section{Aerosol composition from heated tobacco}

Table 1 lists the emissions measured from the heated tobacco samples together with standard deviation values. Total particulate matter (TPM), water, nicotine and nicotine-free-dry-particulate-matter (NFDPM) have also been included. The term NFDPM is a convention used to describe the condense phase material of cigarette smoke. No systematic studies have been published at the present time to account for the full emission composition produced by heating tobacco at lower temperatures. This work chose to focus on a number of known cigarette smoke toxicants, as they cover permanent gases, typical vapour phase and aerosol phase compounds, as well as evaporatively and pyrolytically generated substances. The relatively large standard deviation values reflect the fact these analytical procedures need improvement and optimisation for the different emission matrix from the heated tobacco.

For comparison purpose, the mainstream smoke yields of the cigarette is given in the Additional file 1.

For temperatures under $140^{\circ} \mathrm{C}$, nicotine deliveries were below the reporting limit of the analytical method ( $0.1 \mathrm{mg} / \mathrm{sample})$. Consistent with this, previous studies show that nicotine or nicotine salts begin measurable weight losses above $150^{\circ} \mathrm{C}$ [14]. Nicotine delivery increased rapidly between 160 and $180^{\circ} \mathrm{C}$, again in agreement with the other studies. Across the temperature range, there was also an increase in TPM, water and NFDPM levels. A significant amount of the TPM was made of water, nevertheless a measurable mass of tobacco constituents were released at $100^{\circ} \mathrm{C}$ and above. Carbon monoxide yields were below the reporting limits below $180^{\circ} \mathrm{C}$. Above this temperature (to $200^{\circ} \mathrm{C}$ ), carbon monoxide levels increased with increasing temperatures. During the experiments, no 
Table 1 Amounts of toxicants (mean level $\pm S D, n=3$ ) in the aerosol from heated tobacco at six different temperatures

\begin{tabular}{|c|c|c|c|c|c|c|c|}
\hline \multirow{3}{*}{ 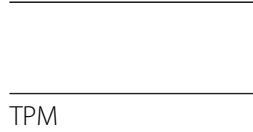 } & \multirow{2}{*}{ unit } & \multicolumn{6}{|c|}{ Tobacco Heating Temperature $\left({ }^{\circ} \mathrm{C}\right)$} \\
\hline & & 100 & 120 & 140 & 160 & 180 & 200 \\
\hline & mg/sample & $11.05 \pm 2.14$ & $13.55 \pm 4.69$ & $23.31 \pm 6.90$ & $19.43 \pm 6.79$ & $30.47 \pm 5.10$ & $32.07 \pm 6.20$ \\
\hline Water & $\mathrm{mg} / \mathrm{sample}$ & $8.41 \pm 1.88$ & $10.13 \pm 3.99$ & $14.47 \pm 0.64$ & $13.11 \pm 3.97$ & $16.73 \pm 1.02$ & $18.81 \pm 1.71$ \\
\hline Nicotine & $\mathrm{mg} / \mathrm{sample}$ & $<0.10$ & $<0.10$ & $0.21 \pm 0.11$ & $0.45 \pm 0.28$ & $1.28 \pm 0.39$ & $1.55 \pm 0.72$ \\
\hline NFDPM & $\mathrm{mg} / \mathrm{sample}$ & $2.62 \pm 0.29$ & $3.38 \pm 0.70$ & $8.64 \pm 6.21$ & $5.88 \pm 2.83$ & $12.46 \pm 3.78$ & $11.71 \pm 6.47$ \\
\hline Ammonia & $\mu \mathrm{g} / \mathrm{sample}$ & $<0.80$ & $<0.80$ & $<0.80$ & $<0.80$ & $<0.80$ & $<0.80$ \\
\hline Carbon monoxide & $\mathrm{mg} / \mathrm{sample}$ & $0.01 \pm 0.02$ & $0.00 \pm 0.00$ & $0.01 \pm 0.02$ & $0.01 \pm 0.02$ & $0.07 \pm 0.04$ & $0.13 \pm 0.02$ \\
\hline Acetaldehyde & $\mu \mathrm{g} / \mathrm{sample}$ & $<1.20$ & $6.5 \pm 1.3$ & $29.8 \pm 4.7$ & $61.9 \pm 6.3$ & $78.4 \pm 1.9$ & $84.6 \pm 15.1$ \\
\hline Acrolein & $\mu \mathrm{g} / \mathrm{sample}$ & $<1.00$ & $<1.00$ & $<1.00$ & $<1.00$ & $<1.00$ & $<1.00$ \\
\hline Crotonaldehyde & $\mu \mathrm{g} / \mathrm{sample}$ & $<1.10$ & $<1.10$ & $<1.10$ & $<1.10$ & $2.0 \pm 0.1$ & $4.1 \pm 0.2$ \\
\hline Formaldehyde & $\mu \mathrm{g} / \mathrm{sample}$ & $<0.90$ & $<0.90$ & $<0.90$ & $<0.90$ & $1.0 \pm 0.1$ & $2.9 \pm 1.2$ \\
\hline Hydrogen cyanide & $\mu \mathrm{g} / \mathrm{sample}$ & $<5.60$ & $<5.60$ & $<5.60$ & $<5.60$ & $<5.60$ & $<5.60$ \\
\hline Catechol & $\mu \mathrm{g} / \mathrm{sample}$ & $<4.00$ & $<4.00$ & $<4.00$ & $<4.00$ & $<4.00$ & $<4.00$ \\
\hline$m$-Cresol & $\mu \mathrm{g} / \mathrm{sample}$ & $<0.40$ & $<0.40$ & $<0.40$ & $<0.40$ & $<0.40$ & $<0.40$ \\
\hline o-Cresol & $\mu \mathrm{g} / \mathrm{sample}$ & $<0.40$ & $<0.40$ & $<0.40$ & $<0.40$ & $<0.40$ & $<0.40$ \\
\hline p-Cresol & $\mu \mathrm{g} / \mathrm{sample}$ & $<0.40$ & $<0.40$ & $<0.40$ & $<0.40$ & $<0.40$ & $<0.40$ \\
\hline Hydroquinone & $\mu \mathrm{g} / \mathrm{sample}$ & $<3.20$ & $<3.20$ & $<3.20$ & $<3.20$ & $<3.20$ & $<3.20$ \\
\hline Phenol & $\mu \mathrm{g} / \mathrm{sample}$ & $<1.60$ & $<1.60$ & $<1.60$ & $<1.60$ & $<1.60$ & $<1.60$ \\
\hline NNN & ng/sample & $0.8 \pm 0.2$ & $1.4 \pm 0.3$ & $2.3 \pm 0.7$ & $1.8 \pm 0.6$ & $1.5 \pm 0.8$ & $1.8 \pm 0.8$ \\
\hline NNK & ng/sample & $0.7 \pm 0.1$ & $0.9 \pm 0.1$ & $1.7 \pm 0.5$ & $1.3 \pm 0.7$ & $1.4 \pm 1.0$ & $0.7 \pm 0.1$ \\
\hline NAB & ng/sample & $<0.18$ & $<0.18$ & $0.3 \pm 0.1$ & $0.2 \pm 0.1$ & $0.4 \pm 0.0$ & $0.4 \pm 0.3$ \\
\hline NAT & ng/sample & $0.4 \pm 0.1$ & $0.8 \pm 0.2$ & $1.3 \pm 0.6$ & $1.1 \pm 0.6$ & $1.5 \pm 1.4$ & $4.2 \pm 3.2$ \\
\hline Acrylonitrile & $\mu \mathrm{g} / \mathrm{sample}$ & $<0.33$ & $<0.33$ & $<0.33$ & $<0.33$ & $<0.33$ & $<0.33$ \\
\hline Benzene & $\mu \mathrm{g} / \mathrm{sample}$ & $<1.42$ & $<1.42$ & $<1.42$ & $<1.42$ & $<1.42$ & $<1.42$ \\
\hline 1,3-Butadiene & $\mu \mathrm{g} / \mathrm{sample}$ & $<2.02$ & $<2.02$ & $<2.02$ & $<2.02$ & $<2.02$ & $<2.02$ \\
\hline Isoprene & $\mu \mathrm{g} / \mathrm{sample}$ & $<8.25$ & $<8.25$ & $<8.25$ & $<8.25$ & $<8.25$ & $<8.25$ \\
\hline Toluene & $\mu \mathrm{g} / \mathrm{sample}$ & $<2.10$ & $<2.10$ & $<2.10$ & $<2.10$ & $<2.10$ & $<2.10$ \\
\hline Acetone & $\mu \mathrm{g} / \mathrm{sample}$ & $<1.50$ & $<1.50$ & $<1.50$ & $3.6 \pm 1.1$ & $7.0 \pm 0.5$ & $8.4 \pm 3.7$ \\
\hline Butyraldehyde & $\mu \mathrm{g} / \mathrm{sample}$ & $<1.20$ & $<1.20$ & $5.4 \pm 0.7$ & $10.5 \pm 0.9$ & $10.9 \pm 0.7$ & $9.5 \pm 2.2$ \\
\hline Methyl ethyl ketone & $\mu \mathrm{g} / \mathrm{sample}$ & $<1.20$ & $<1.20$ & $<1.20$ & $<1.20$ & $1.3 \pm 0.0$ & $1.9 \pm 0.5$ \\
\hline Propionaldehyde & $\mu \mathrm{g} / \mathrm{sample}$ & $<0.95$ & $<0.95$ & $<0.95$ & $1.7 \pm 0.3$ & $3.5 \pm 0.2$ & $5.6 \pm 0.8$ \\
\hline Resourcinol & $\mu \mathrm{g} / \mathrm{sample}$ & $<0.40$ & $<0.40$ & $<0.40$ & $<0.40$ & $<0.40$ & $<0.40$ \\
\hline
\end{tabular}

blanks were run to account for the atmospheric carbon monoxide levels. Natural background carbon monoxide concentration has been reported to be of $0.04 \mathrm{ppm}[26]$, thus the reporting limit of $0.01 \mathrm{mg} / \mathrm{cig}$ (approximately $100 \mathrm{ppm}$ ) from this work is too high to show any contribution from environmental carbon monoxide. Baker's study on cellulose and tobacco [16] pointed out that carbon monoxide was formed mainly by a low-temperature decomposition of tobacco constituents around and above $180^{\circ} \mathrm{C}$.

The levels of other analytes also increased gradually with rising temperature, including acetaldehyde (120 to $200^{\circ} \mathrm{C}$ ), crotonaldehyde (180 to $200^{\circ} \mathrm{C}$ ), formaldehyde $\left(180\right.$ to $\left.200^{\circ} \mathrm{C}\right)$, acetone $\left(160\right.$ to $\left.200^{\circ} \mathrm{C}\right)$, butyraldehyde
(140 to $200^{\circ} \mathrm{C}$ ), methyl ethyl ketone $\left(180\right.$ to $200^{\circ} \mathrm{C}$ ) and propionaldehyde $\left(160\right.$ to $\left.200^{\circ} \mathrm{C}\right)$. Trace amounts of these compounds have been reported in smokeless tobacco products [27], but the volatility of these compounds means that were they to contribute to the quantities measured in this work then they would be observed at all temperatures. This was not the case, and therefore it can be concluded that the majority of these compounds are formed from the tobacco decomposition. It is known they can be formed by pyrolytic decomposition of carbohydrates and tobacco structural polymers (e.g., cellulose, pectins and sugars) [28-31]. More recent studies have shown that pectin undergoes phase transformation between 
150 and $180^{\circ} \mathrm{C}$ before an exothermic degradation $[32,33]$. The slow heating rate experienced by the tobacco inside the furnace may allow this type of thermal decomposition to occur to some extent, hence contributing to the measured levels.

For all six temperatures studied, three tobacco-specific nitrosamines or TSNAs (NNN, NNK and NAT) were quantifiable, but there was no consistent trend across the temperature range. $\mathrm{NAB}$ was found at $140^{\circ} \mathrm{C}$ and above. These nitrosamine compounds are known to be present in the tobacco leaf (Table 2) and can be directly transferred into cigarette smoke [1,34]. The fact that they were transferable at these low temperatures may be attributed to their structural similarities to nicotine and further similar thermochemical properties (e.g., the boiling point of $\mathrm{NNN}$ is $154^{\circ} \mathrm{C}$ at 0.2 Torr [35]). Pyrosynthesis of these nitrosamines have been reported in cigarette smoke [36] but the likelihood of this occurrence at the low temperatures in this work is low. As a possible explanation for the inconsistent yields, the possibility of analytical contamination was checked; during the LC-MS/MS analysis of the nitrosamines, blank solvent samples were run before and after as quality control samples; however, no contamination or carryover was found. For other compounds, such as acrylonitrile, $\mathrm{HCN}$ and phenols, the absence of detectable amount of these compounds in the emissions from the heated tobacco samples suggest that higher temperatures may be required for their formation.

Heating tobacco from periphery at the temperatures used in this study significantly minimizes pyrolysis and prevents combustion reactions. Figure 2 also reveals a pronounced cooling effect caused by a puff, especially at the lower heating temperature $\left(100^{\circ} \mathrm{C}\right)$. At the heater temperatures above $100^{\circ} \mathrm{C}$, the thermal lag in the centre of the tobacco rod as demonstrated by the temperature plateau around $100^{\circ} \mathrm{C}$ was a visible feature (Figure 2) and linked to the energy required to release water. All of these are expected to influence the yields and relative proportionalities of the analytes measured in Table 1.

In Figure 3, the yields of six analytes that were quantifiable under the full or majority of the temperatures were analysed using a pseudo-Arrhenius plot; the objective was to see whether their release could be empirically modelled to differentiate their release mechanisms. This is empirical because the tobacco rod could not be heated to the target temperature instantaneously when it was introduced into the furnace. The emission values plotted in Figure 3 were the results of accumulated release from a range of temperatures leading up to the set temperature. Hence this pseudo-Arrhenius approach cannot be used to calculate accurate kinetic parameters for the generation of these compounds, but comparison of relative trends between the compounds observed are valid. Reasonable linearity was seen in the pseudo-Arrhenius plots for acetaldehyde, nicotine, water and NFDPM values. As Table 1 shows, the measured TPM consisted of a large portion of water and a significant level of nicotine above $160^{\circ} \mathrm{C}$. Thus, the calculated NFDPM captured the remaining condensed phase matter in the aerosol excluding these two compounds. A full analysis of the chemical composition of this condensed phase matter (NFDPM) is beyond the objective of this study.

Gradients obtained from linear regression in these plots gave the values for the pseudo-first order activation energy listed in Table 3. The value estimate for water, at $11.5 \mathrm{~kJ} \mathrm{~mol}^{-1}$ is about 3-4 times lower than the

Table 2 Tobacco blend and rod physical parameters

\begin{tabular}{lll}
\hline Tobacco rod length & $\mathrm{mm}$ & 61.0 \\
Total cigarette length & $\mathrm{mm}$ & 83.0 \\
Filter type* & Cingle section & 598.0 \\
Tobacco weight & $\mathrm{mg}$ & 50 \\
Cigarette paper & Coresta Unit** & 54.0 \\
Unlit cigarette pressure drop & $\mathrm{mm}$ water gauge & 3.25 \\
Blend nicotine (dry weight basis) & $\%$ & 14.5 \\
Total sugar (dry weight basis) & $\%$ & 97 \\
$N$-nitrosonornicotine (NNN) & ng/gram of tobacco & 43 \\
4-(N-methylnitroso amino)-1-(3-pyridinyl)-1-butanone (NNK) & ng/gram of tobacco & 12 \\
$N$-nitrosoanabasine (NAB) & ng/gram of tobacco & 151 \\
$N$-nitrosoanatabine (NAT) & ng/gram of tobacco & 11.0 \\
Tobacco moisture & $\%$ & 4.1
\end{tabular}

*The filter was removed from the tobacco rod for the heating experiments. ${ }^{*}$ Coresta unit is defined by the flow of air $\left(\mathrm{cm}^{3}\right.$ min ${ }^{-1}$ ) passing through $1 \mathrm{~cm}^{2}$ surface of the paper at a measuring pressure of $1.00 \mathrm{kPa}\left(\mathrm{cm}^{3} \mathrm{~min}^{-1} \mathrm{~cm}^{-2}\right.$ at $\left.1 \mathrm{kPa}\right)$.

***NFDPM stands for "nicotine-free-dry-particulate-matter"; a convention used to compare yields made from machine-smoked cigarettes. 

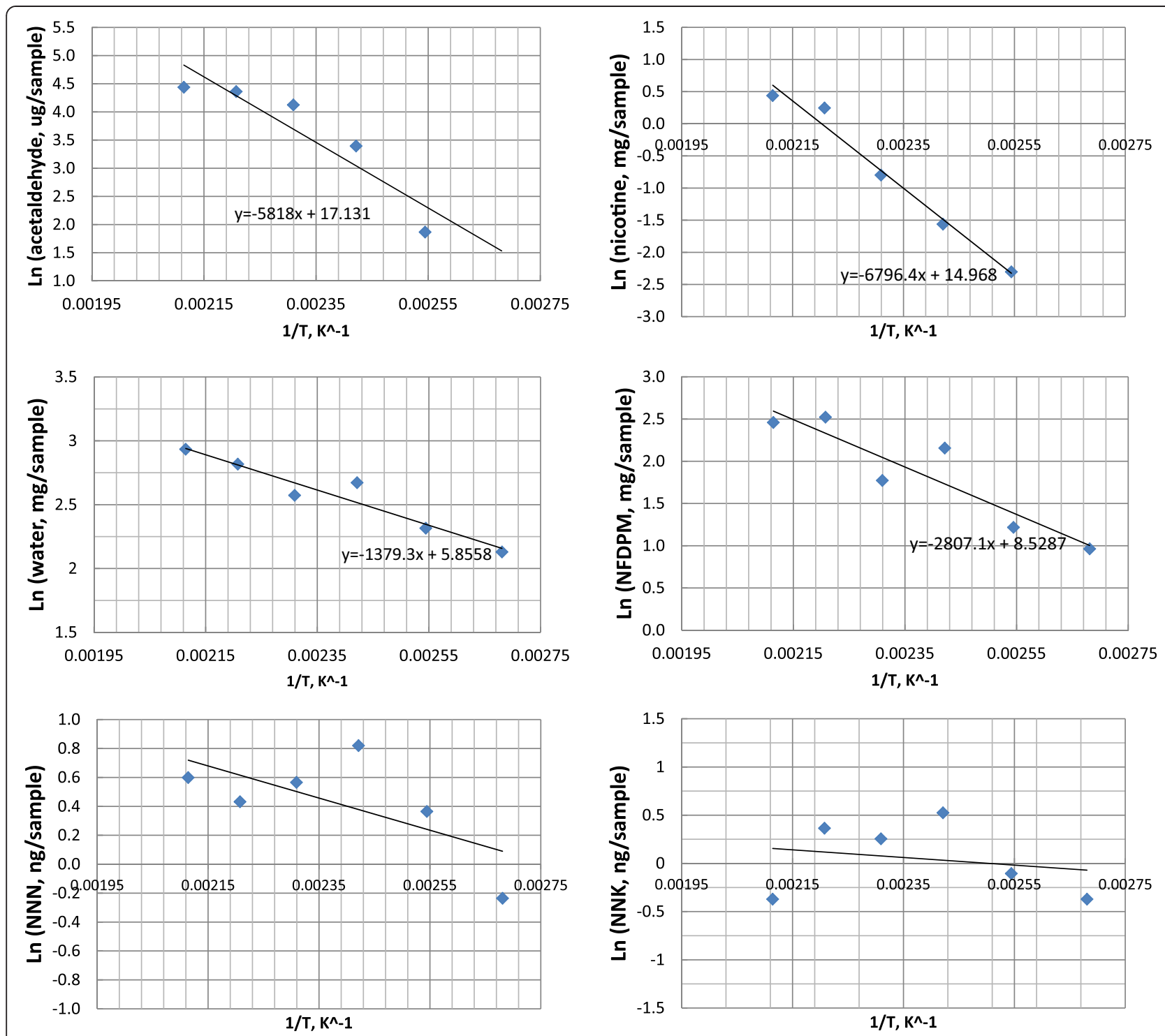

Figure 3 Arrhenius plots for the six analytes quantified in the heated tobacco aerosol.

reference values for the enthalpy of vaporisation of water over the temperature range $100-200^{\circ} \mathrm{C}$ [37]. The enthalpy of vaporisation of pure nicotine of $53.3\left(\mathrm{KJ} \mathrm{mol}^{-1}\right)$ [38] is similar to the value estimated in this work, but previous thermal studies of nicotine evolution from the type of salts found in tobacco have identified effective activation energies for nicotine release of the order of $120\left(\mathrm{KJ} \mathrm{mol}^{-1}\right)$, consistent with bond breaking of the nicotine salt and evaporation of the unprotonated nicotine. This value is about 2.5 times higher than that estimated in the current work. Hence, the non-isothermal nature of the current experiment may

Table 3 Pseudo-activation energies estimated from tobacco heating experiments and literature values

\begin{tabular}{|c|c|c|c|}
\hline Compound & Pseudo-activation energy $\left(\mathrm{KJ} \mathrm{mol}^{-1}\right)$ & Enthalpy of vapourisation $\left(\mathrm{KJ} \mathrm{mol}^{-1}\right)$ & Literature value [40] $\left(\mathrm{KJ} \mathrm{mol}^{-1}\right)$ \\
\hline Water & 11.5 & $36.3 \sim 40.7$ between $100-200^{\circ} \mathrm{C}$ & - \\
\hline Nicotine & 56.5 & 53.3 & - \\
\hline Nicotine salts & & & 115 \\
\hline Acetaldehyde & 48.4 & $26 .-27.6$ & - \\
\hline NFDPM & 23.3 & - & - \\
\hline
\end{tabular}


be behind these underestimates. With this in mind, the effective activation energy for acetaldehyde release at $48.4 \mathrm{~kJ} \mathrm{~mol}^{-1}$, points to activation energies consistent with bond breaking rather than vapourisation, consistent with previous work showing it to be generated from thermal decomposition of sugars, pectin and cellulosic ingredients within tobacco [39]. The lower pseudo-activation energy for NFDPM of 23.3(KJ $\mathrm{mol}^{-1}$ ) measured in this work points to a mixture of evaporative and bond breaking routes. Poor linearity can be seen for NNN and NNK despite their structural similarities to nicotine. This might be attributed to their low levels in their emissions. In summary, the approaches described the potential to deduce useful information for different classes of compounds found in low-temperature heating of tobacco.

From the emissions data obtained on the heated tobacco samples, estimates could be made of the degree to which the reservoir of the studied compounds within the tobacco rod were exhausted by the 7 puffs used in this study. This is shown in Table 4 for water, nicotine and three tobacco-specific nitrosamines. With the lowest boiling point among these compounds, the percentage of water released increased gradually with the increasing set heater temperature, to a final level of ca. $29 \%$ of the blend water content at $200^{\circ} \mathrm{C}$. The percentage of nicotine released under the 7 puffs was only ca. $9 \%$ of the blend nicotine. The percentage released for the three TSNAs were even lower. Assuming first order kinetic processes, and using the integrated form of the rate equation, it was estimated that under the experimental conditions used the tobacco rod half life "times" would be of approximately 16 puffs for water, 50 puffs for nicotine and 2-300 puffs for TSNAs under $200^{\circ} \mathrm{C}$ heating conditions. Therefore tobacco heated to $200^{\circ} \mathrm{C}$ can generate emissions for a substantially longer period than a burning cigarette. This demonstrates the difficulty in setting a fixed puff number for the practical determination of its emissions from a low-temperature heated tobacco sample. Interactions between tobacco weight, tobacco composition, tobacco format, heating temperature,

Table 4 Percentage of water, nicotine and three TSNAS released at the different temperatures against their levels in the tobacco sample

\begin{tabular}{lllllll}
\hline & \multicolumn{7}{l}{ Tobacco Heating Temperature $\left({ }^{\circ} \mathbf{C}\right)$} \\
\cline { 2 - 8 } & $\mathbf{1 0 0}$ & $\mathbf{1 2 0}$ & $\mathbf{1 4 0}$ & $\mathbf{1 6 0}$ & $\mathbf{1 8 0}$ & $\mathbf{2 0 0}$ \\
\hline Water released (\%) & 13 & 15 & 22 & 20 & 25 & 29 \\
Nicotine released (\%) & - & - & - & 3 & 7 & 9 \\
NNN released (\%) & 0.8 & 1.4 & 2.4 & 1.9 & 1.5 & 1.9 \\
NNK released (\%) & 1.6 & 2.1 & 4.0 & 3.0 & 3.3 & 1.6 \\
NAT released (\%) & 0.3 & 0.5 & 0.9 & 0.7 & 1.0 & 2.8 \\
\hline
\end{tabular}

puffing parameters, etc., all contribute to the total emission levels.

\section{Experimental \\ Tobacco heating device}

Figure 4 is a schematic diagram of the tube furnace designed to accurately heat a quantity of cut tobacco (comparable to the amount used in a conventional cigarette) up to $400^{\circ} \mathrm{C}$ within $\pm 5^{\circ} \mathrm{C}$. A separate $\mathrm{AC}$-mains powered control unit was used to regulate the heat supplied to a wound wire heater. The furnace had a stainless steel casing with thermal shielding for safe handling. The outer dimensions were such that it was compatible with commercial linear smoke machines, allowing up to 10 devices to be puffed simultaneously to generate aerosol emissions. Tobacco samples in cigarette rod format were loaded from one end of the device (right, in Figure 4), hosted within the central segment of a $92 \mathrm{~mm}$ long quartz tube $(10 \mathrm{~mm}$ outer diameter and $8 \mathrm{~mm}$ inner diameter). The tube had a stainless steel end-cap at one end (right, in Figure 4) and a connection tube on the other. The connection tube was approximately $30 \mathrm{~mm}$ long and of $8 \mathrm{~mm}$ outer diameter and $4 \mathrm{~mm}$ internal diameter. It fitted a Cambridge pad holder (a standard fixture used to trap particulate or aerosol). The stainless steel end-cap on the right had one centre hole ( $3 \mathrm{~mm}$ in diameter) that was designed to accommodate an end-piercing thermocouple to monitor the internal temperature of the tobacco being heated and also allowed airflow to be drawn through. Due to the fact that the furnace was mains-powered, the heating elements achieved a set temperature almost instantaneously; the actual heating rate for the tobacco sample was variable and determined by the heating time, given the identical quartz tubes and tobacco weights used.

\section{Tobacco sample}

The tobacco used in this study was already manufactured into a cigarette form (ca. $8 \mathrm{~mm}$ in diameter and $83 \mathrm{~mm}$ long, see Table 2), as this was thought to give a more consistent tobacco weight and density control along the length of the heating zone. Loose forms of tobacco or different materials may also be heated by this method. For each heating experiment, the filter of the cigarette was removed as its presence would have introduced the possible presence of filter components and thermolysis products into the aerosol. The remaining tobacco rod was inserted $15 \mathrm{~mm}$ from the connection end of the quartz tube. The furnace was then switched on and allowed to reach a set temperature before the loaded quartz tube was inserted into the heating zone. In this way, the heating profile of the tobacco sample was only determined by the sample. Once in position, the tobacco sample was heated for two minutes at the set temperature before puffing was initiated at the set temperature. A total 


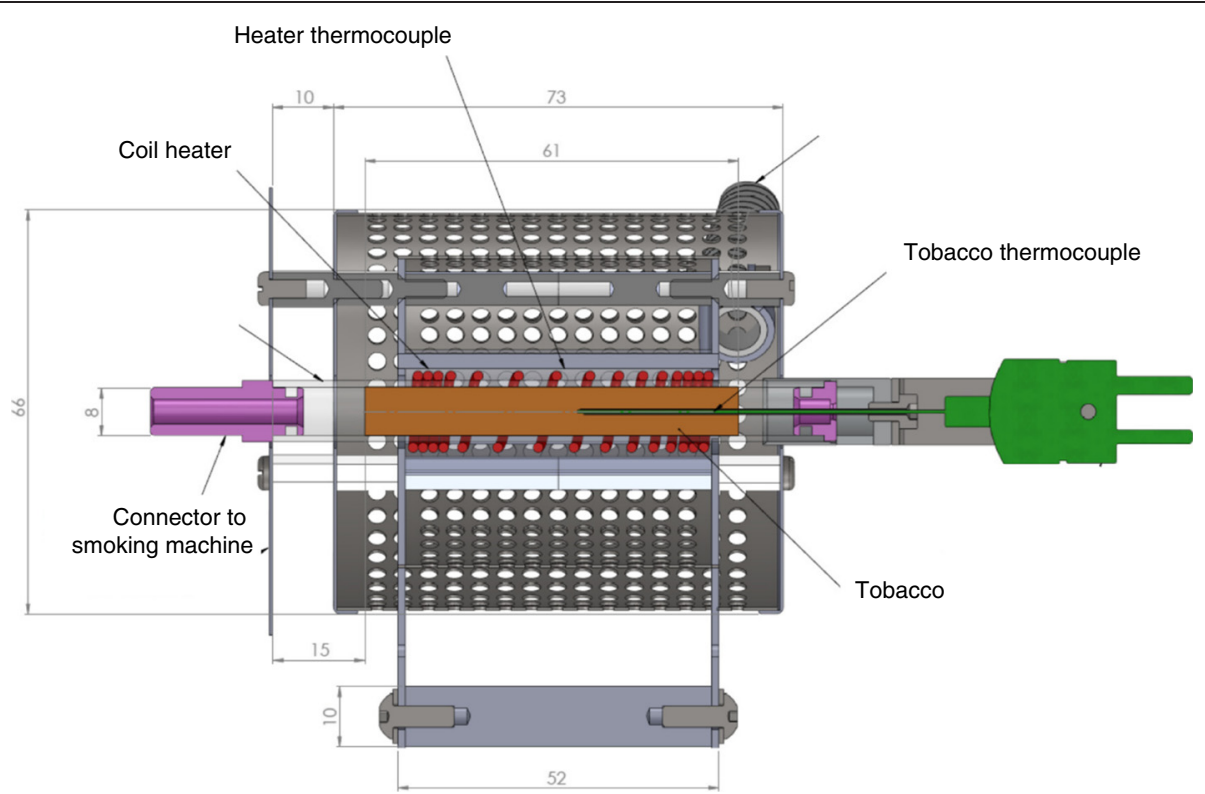

Figure 4 A schematic diagram of the tube furnace for low-temperature heating (the dimension shown are in $\mathrm{mm}$ ).

of 7 puffs were taken for each sample - this was intended to mimic the duration of a cigarette being smoked (and was equivalent to the ISO smoking puff number of this cigarette; it was not intended to "exhaust the content" of the tobacco sample. The tobacco used in this study was a single grade Virginia type, designed for research purpose only. A number of physical and chemical parameters for the cigarettes were measured and provided in Table 2.

\section{Aerosol chemical analyses}

Chemical analyses of the aerosol emissions followed the procedures listed in Table 5. These are procedures developed for cigarette smoke analyses. At each temperature $\left(100,120,140,160,180,200^{\circ} \mathrm{C}\right)$, three replicates were taken for each heated tobacco sample using a single furnace with an unused tobacco rod. Each furnace was clamped into position and connected to the smoking port of a SM450 linear cigarette smoking machine (Cerulean,

Table 5 Eight analytical methods used and their targeted analytes in aerosol

\begin{tabular}{|c|c|c|c|}
\hline Analyte(s) & Aerosol collection & Analytical method & $\begin{array}{l}\text { No of } \\
\text { replicates }\end{array}$ \\
\hline Ammonia & $\begin{array}{l}\text { Liquid impinger/ } \\
0.05 \text { M sulphuric } \\
\text { acid }\end{array}$ & Ion chromatography (IC) & 3 \\
\hline Carbon monoxide & Tedlar bag & Non dispersive infrared analyser & 3 \\
\hline $\begin{array}{l}\text { Nicotine, total particulate matter (TPM), } \\
\text { nicotine-free-dry-particulate-matter (NFDPM), water }\end{array}$ & $\begin{array}{l}\text { Cambridge filter } \\
\text { pad }\end{array}$ & $\begin{array}{l}\text { Gas chromatography (GC) with thermal } \\
\text { conductivity for nicotine and GC-flame ionisation } \\
\text { detection for water }\end{array}$ & 3 \\
\hline $\begin{array}{l}\text { Acetaldehyde, acetone, acrolein, butyraldehyde, } \\
\text { crotonaldehyde, formaldehyde, methylethylketone (MEK), } \\
\text { propionaldehyde }\end{array}$ & $\begin{array}{l}\text { Liquid impinger/ } \\
\text { DPNH }\end{array}$ & $\begin{array}{l}\text { Ultraviolet-high performance liquid } \\
\text { chromatography (UV-HPLC) }\end{array}$ & 3 \\
\hline Hydrogen cyanide & $\begin{array}{l}\text { Liquid impinger/ } \\
\text { aqueous sodium } \\
\text { hydroxide }\end{array}$ & Continuous flow analysis & 3 \\
\hline $\begin{array}{l}\text { Catechol, cresol (o-, } m \text { - \& } p \text {-), hydroquinone, phenol, } \\
\text { resourcinol }\end{array}$ & $\begin{array}{l}\text { Cambridge filter } \\
\text { pad }\end{array}$ & GC/MS & 3 \\
\hline $\begin{array}{l}\text { N-nitrosonornicotine (NNN), 4-(N-methylnitroso amino)-1-(3-pyri- } \\
\text { dinyl)-1-butanone (NNK), N-nitrosoanabasine (NAB), N-nitrosoa- } \\
\text { natabine (NAT) }\end{array}$ & $\begin{array}{l}\text { Cambridge filter } \\
\text { pad }\end{array}$ & $\begin{array}{l}\text { Liquid chromatography-Mass spectrometry/Mass } \\
\text { spectrometry (LC-MS/MS) }\end{array}$ & 3 \\
\hline Acrylonitrile, benzene 1,3-butadiene isoprene, toluene & $\begin{array}{l}\text { Liquid impinger/ } \\
\text { chilled methanol, } \\
-77^{\circ} \mathrm{C}\end{array}$ & Gas chromatography-mass spectrometry (GC-MS) & 3 \\
\hline
\end{tabular}


Milton Keynes, Bucks, MK14 6LY, UK). Puff parameters used were: $35 \mathrm{~mL}$ puff volume, $2 \mathrm{~s}$ puff duration, one puff every $60 \mathrm{~s}$; this protocol was based on an ISO standard machine-smoking method [41].

\section{Thermogravimetric analyses (TGA)}

TGA (PerkinElmer, STA 6000) were also performed on the tobacco to provide an overview of its thermal behaviour. For this experiment, between 13.4 to $13.8 \mathrm{mg}$ of tobacco was loaded into an alumina crucible. For each TGA experiment, baseline temperature $\left(30^{\circ} \mathrm{C}\right)$ was reached before the crucible with the tobacco sample was heated in air under 30,40 and $50^{\circ} \mathrm{C} \mathrm{min}{ }^{-1}$ heating rates. These heating rates were broadly in line with that measured from the centre of the tobacco rod (see Figure 3); the heating rate experienced by the surface of the tobacco rod would be faster. Three replicates were run under each heating rate and averaged prior to interpretation. First derivative of the averaged weight loss (DTG) were also obtained. Prior to all the experiments, the tobacco samples were conditioned at $22^{\circ} \mathrm{C}$ and $60 \%$ relative humidity for at least $48 \mathrm{hr}$.

\section{Conclusions}

In this study, we have developed an experimental method to generate emissions from tobacco samples that was heated between 100 and $200^{\circ} \mathrm{C}$. This approach was applied to understand main thermophysical and thermochemical processes behind a number of compounds found in the aerosol generated by a smoking machine. For the majority of the compounds targeted, the temperatures were either too low for their presence in the aerosol or the amounts generated fell below the detection limits of the analytical methods used. For those compounds that were quantified

- Carbon monoxide, acetaldehyde, NNN and NNK were quantifiable at $140^{\circ} \mathrm{C}$ and $160^{\circ} \mathrm{C}$, and crotonaldehyde and formaldehyde were quantifiable at $180^{\circ} \mathrm{C}$ and $200^{\circ} \mathrm{C}$.

- Water, NFDPM, acetaldehyde and nicotine were found to obey pseudo-Arrhenius kinetics with increasing activation energy values. These appeared to agree with their known thermal release mechanisms, which ranging from evaporation, distillation to decomposition.

\section{Additional file}

Additional file 1: Supplement Material - Toxicants in the test cigarette mainstream smoke.

\section{Competing interests}

The authors declare that they have no competing interests.

\section{Authors' contributions}

MF carried out the experimental work. All the other co-authors participated in the data analyses and draft the manuscript. All authors read and approved the final manuscript.

\section{Acknowledgements}

Mr N. Oakes (Turquoise Engineering, UK) designed and manufactured the tube furnace used in this study. Analytical \& Support Services of GR\&D, British American Tobacco provided chemical analyses. British American Tobacco Investment provided funding for this work.

Received: 19 December 2014 Accepted: 1 April 2015

Published online: 16 April 2015

\section{References}

1. Baker RR. Smoke Chemistry, in Tobacco: production, chemistry and technology. In: Layten DD, Nielsen MT, editors. Oxfors OX2 OEL: Blackwell Science Ltd.; 1999.

2. Borgerding M, Klus $\mathrm{H}$. Analysis of complex mixtures - cigarette smoke. Exp Toxicol Pathol. 2005;57 Suppl 1:43-73.

3. Rodgman A, Perfetti TA. The chemical composition of tobacco and tobacco smoke. Boca Raton: CRC Press; 2013.

4. Baker RR. Smoke generation inside a burning cigarette: modifying combustion to develop cigarettes that may be less hazardous to health. Progr Energ Combust Sci. 2006;32:373-85.

5. RJ Rynolds Tobacco Company. Chemical and biological studies: new cigarette prototype that heat instead of burn tobacco. Winston-Salem, NC: R.J. Reynolds Tobacco Co; 1988. p. 27102.

6. Eclipse Expert Panel. A safe cigarette? a comparative study. A concensus report. Inhal Toxicol. 2000;12 Suppl 5:1-48.

7. Roemer E, Stabbert R, Veltel D, Müller BP, Meisgen TJ, Schramke H, et al. Reduced toxicological activity of cigarette smoke by the addition of ammonium magnesium phosphate to the paper of an electrically heated cigarette: smoke chemistry and in vitro cytotoxicity and genotoxicity. Toxicol in Vitro. 2008:22:671-81.

8. Patskan G, Reininghaus W. Toxicological evaluation of an electrically heated cigarette. Part 1: overview of technical concepts and summary of findings. J Appl Toxicol. 2003;23:323-8.

9. Stabber R, Voncken P, Rustemeier K, Haussmann H-J, Roemer E, Shaffernicht $\mathrm{H}$, et al. Toxicological evaluation of an electrically heated cigarette. Part 2: chemical composition of mainstream smoke. J Appl Toxicol. 2003;23:329-39.

10. Roethig HJ, Kinser RD, Lau RW, Walk R-A, Wang N. Short-term exposure evaluation of adult smokers switching from conventional to first generation electrically heated cigarettes during controlled smoking. J Clin Pharmacol. 2005;45:133-45.

11. Schorp MK, Tricker AR, Dempsey R. Reduced exposure evaluation of an electrically heated cigarette smoking system. Part 1: Non-clinical and clinical insights. Regul Toxicol Pharmacol. 2012;64 Suppl 2:1-10.

12. Zenzen V, Diekmann J, Gerstenberg B, Weber S, Wittke S, Schorp MK Reduced exposure evaluation of an electrically heated cigarette smoking system. Part 2: smoke chemistry and in vitro toxicological evaluation using smoking regimens reflecting human puffing behaviour. Regul Toxicol Pharmacol. 2012;64 Suppl 2:11-34

13. Perfetti TA, Norman AB, Gordon BM, Coleman III WM, Morgan WT, Dull GM, et al. The transfer of nicotine from nicotine salts to mainstream smoke. Beitr Tabakforsch Int. 2000;19:141-60.

14. Riggs DM, Perfett TA. Thermochemical properties of nicotine salts. Beitr Tabakforsch Int. 2001;19:289-95.

15. Seeman Jl, Carchman RA. The possible role of ammonia toxicity on the exposure, deposition, retention, and the bioavailability of nicotine during smoking. Food Chem Toxicol. 2008:46:1863-81.

16. Baker RR. A review of pyrolysis studies to unravel reaction steps in burning tobacco. J Anal Appl Pyrol. 1987;11:555-73.

17. Schlotzhauer WS, Chortyk OT. Recent advances in studies on the pyrosyntehsis of cigarette smoke constituents. J Anal Appl Pyrol. 1987:12:193-222.

18. Burton H, Childs Jr G. The thermal degradation of tobacco: Vl. influence of extraction on the formation of some major gas phase constituents. Beitr Tabakforsch. 1975;8:174-80. 
19. Burton H, Childs Jr G. Thermal decomposition of tobaccos: Vll: influence of atmosphere on the formation of gas phase constituents. Beitr Tabakforsch 1977:9:45-52.

20. Czégény Z, Blazsó M, Várhegyi G, Jakab E, Liu C, Nappi L. Formation of selected toxicants from tobacco under different pyrolysis conditions. J Anal Appl Pyrol. 2009;85:47-53.

21. Adam T, Streibel T, Mitschke S, Mühlberger F, Baker RR, Zimmermann R. Application of time-of-flight mass spectrometry with laser-based photoionization methods for analytical pyrolysis of PVC and tobacco. J Anal Appl Pyrol. 2005;74:454-64.

22. Adam T, Ferge T, Mitschke S, Streibel T, Baker RR, Zimmermann R. Discrimination of three tobacco types (Burley, Virginia and Oriental) by pyrolysis single-photon ionisation-time-of-flight mass spectrometry and advanced statistical methods. Anal Bioanal Chem. 2005;381:487-99.

23. Torikai K, Yoshida S, Takahashi $\mathrm{H}$. Effects of temperature, atmosphere and pH on the generation of smoke compounds during tobacco pyrolysis. Food Chem Toxicol. 2004;42:1409-17.

24. Torikaiu K, Uwano Y, Nakamori T, Tarora W, Takahashi H. Study on tobacco components involved in the pyrolytic generation of selected smoke constituents. Food Chem Toxicol. 2005;43:559-68.

25. Hertz R, Streibel T, Liu C, McAdam K, Zimmermann R. Microprobe sampling — photo ionization-time-of-flight mass spectrometry for in situ chemical analysis of pyrolysis and combustion gases: examination of the thermo-chemical processes within a burning cigarette. Anal Chim Acta. 2012;714:104-13.

26. World Health Organization. Carbon Monoxide (Environmental Health Criteria; 213). Geneva, Switzerland. 1999

27. Stepanov I, Jensen J, Hatsukami D, Hecht SH. New and traditional smokeless tobacco: comparison of toxicant and carcinogen levels. Nicotine Tob Res. 2008;10:1773-82

28. Baker RR, Bishop $\sqcup$. The pyrolysis of tobacco ingredients. J Anal Appl Pyrol 2004:71:223-311.

29. Baker RR, Bishop $\amalg$. The pyrolysis of non-volatile tobacco ingredients using a system that simulates cigarette combustion conditions. J Anal Appl Pyrol. 2005;74:145-70.

30. Paine JB, Pithawalla YB, Naworal JD. Carbohydrate pyrolysis mechanisms from isotopic labelling. Part 2: the pyrolysis of D-glucose: general disconnective analysis and the formation of C1 and C2 carbonyl compounds by electrocyclic fragmentation mechanisms. J Anal Appl Pyrol. 2008;82:10-41.

31. Zhou S, Xu YB, Wang CH, Tian ZF. Pyrolysis behaviour of pectin under the conditions that simulate cigarette smoking. J Anal Appl Pyrol. 2014;91:232-40

32. lijima M, Nakamura K, Hatakeyama T, Hatakeyama H. Phase transition of pectin with sorbed water. Carbohyd Polym. 2000;41:101-6.

33. Einhorn-Stoll U, Kunzek H, Dongowski G. Thermal analysis of chemically and mechanically modified pectins. Food Hydrocolloid. 2007;21:1101-12.

34. Moldoveanu SC, Borgerding MF. Formation of tobacco specific nitrosamines in mainstream cigarette smoke: Part 1, FTC smoking. Beitr Tabakforsch Int. 2008;23:19-31

35. IARC Monographs on the Evaluation of Carcinogenic Risks to Humans, Volume 89 (2007), Smokeless Tobacco and Some Tobacco-specific N-Nitrosamines. Lyon CEDEX 08, France.

36. Hoffmann I, Hoffmann D. The changing cigarette: chemical studies and bioassays. In: Burns DM, Benowitz NL, editors. Risks associated with smoking cigarettes with Low machine measured yields of Tar and nicotine. Bethesda, MD, USA: US Department of Health and Human Services, Public Health Services, National Institute of Heath, National Cancer Institute; 2001. p. 159-91.

37. Marsh KN, editor. Recommended reference materials for the realization of physicochemical properties. Oxford: Blackwell; 1987.

38. Chickos JS, William Jr EA. Enthalpies of vaporization of organic and organometallic compounds, 1880-2002. J Phys Chem Ref Data. 2003:32:519-878.

39. Piadé J-J, Wajrock S, Jaccard G, Janeke G. Formation of mainstream cigarette smoke constituents prioritized by the world health organization - yield patterns observed in market surveys, clustering and inverse correlations. Food Chem Toxicol. 2013:55:329-47.

40. Seeman JI, Fournier JA, Paine III JB, Waymack BE. The form of nicotine in tobacco. thermal transfer of nicotine and nicotine acid salts to nicotine in the gas phase. J Agric Food Chem. 1999;47:5133-45.

41. ISO 3308:2012, Routine analytical cigarette-smoking machine - Definitions and standard conditions. Geneva, Switzerland.

\section{Publish with ChemistryCentral and every scientist can read your work free of charge \\ "Open access provides opportunities to our colleagues in other parts of the globe, by allowing anyone to view the content free of charge." \\ W. Jeffery Hurst, The Hershey Company. \\ - available free of charge to the entire scientific community \\ - peer reviewed and published immediately upon acceptance \\ - cited in PubMed and archived on PubMed Central \\ - yours - you keep the copyright \\ Submit your manuscript here: \\ http://www.chemistrycentral.com/manuscript/<smiles>c1ccccc1</smiles> \\ Chemistry Central}

